\title{
Common NFKBIL2 polymorphisms and susceptibility to pneumococcal disease: a genetic association study
}

Stephen J Chapman ${ }^{1,2,3^{*}}$, Chiea C Khor ${ }^{1,4}$, Fredrik O Vannberg ${ }^{1}$, Anna Rautanen ${ }^{1}$, Andrew Walley ${ }^{1,5}$, Shelley Segal ${ }^{6}$, Catrin E Moore ${ }^{1,7}$, Robert JO Davies ${ }^{3 \wedge}$, Nicholas P Day ${ }^{7}$, Norbert Peshu ${ }^{8}$, Derrick W Crook ${ }^{9}$, James A Berkley ${ }^{8}$, Thomas N Williams $6,8,9,10,11$, J Anthony Scott ${ }^{8}$, Adrian VS Hill ${ }^{1}$

\begin{abstract}
Introduction: Streptococcus pneumoniae remains a major global health problem and a leading cause of death in children worldwide. The factors that influence development of pneumococcal sepsis remain poorly understood, although increasing evidence points towards a role for genetic variation in the host's immune response. Recent insights from the study of animal models, rare human primary immunodeficiency states, and population-based genetic epidemiology have focused attention on the role of the proinflammatory transcription factor NF- $\kappa \mathrm{B}$ in pneumococcal disease pathogenesis. The possible role of genetic variation in the atypical NF- $\kappa$ B inhibitor $\mid \kappa B-R$, encoded by NFKBIL2, in susceptibility to invasive pneumococcal disease has not, to our knowledge, previously been reported upon.
\end{abstract}

Methods: An association study was performed examining the frequencies of nine common NFKBIL2 polymorphisms in two invasive pneumococcal disease case-control groups: European individuals from hospitals in Oxfordshire, UK (275 patients and 733 controls), and African individuals from Kilifi District Hospital, Kenya (687 patients with bacteraemia, of which 173 patients had pneumococcal disease, together with 550 controls).

Results: Five polymorphisms significantly associated with invasive pneumococcal disease susceptibility in the European study, of which two polymorphisms also associated with disease in African individuals. Heterozygosity at these loci was associated with protection from invasive pneumococcal disease (rs760477, Mantel-Haenszel $2 \times 2$ $\chi^{2}=11.797, P=0.0006$, odds ratio $=0.67,95 \%$ confidence interval $=0.53$ to 0.84 ; rs 4925858 , Mantel-Haenszel $2 \times$ $2 \chi^{2}=9.104, P=0.003$, odds ratio $=0.70,95 \%$ confidence interval $=0.55$ to 0.88 ). Linkage disequilibrium was more extensive in European individuals than in Kenyans.

Conclusions: Common NFKBIL2 polymorphisms are associated with susceptibility to invasive pneumococcal disease in European and African populations. These findings further highlight the importance of control of NF- $\kappa$ B in host defence against pneumococcal disease.

\section{Introduction}

Respiratory infection is the single largest contributor to the global burden of disease and the leading cause of death in children worldwide $[1,2]$. Streptococcus pneumoniae (the pneumococcus) remains the most common cause of community-acquired pneumonia in Europe and

\footnotetext{
* Correspondence: schapman@well.ox.ac.uk

^Deceased

'The Wellcome Trust Centre for Human Genetics, University of Oxford, Roosevelt Drive, Oxford OX3 7BN, UK

Full list of author information is available at the end of the article
}

the United States [3]. In addition to pneumonia, pneumococcal infection may also manifest as invasive disease, defined by the isolation of S. pneumoniae from a normally sterile site such as blood (bacteraemia) or cerebrospinal fluid (meningitis). Although asymptomatic colonisation of the nasopharynx by the pneumococcus is widespread in the population, invasive pneumococcal disease (IPD) occurs in only a minority of individuals $[4,5]$. The factors that influence development of invasive disease remain poorly understood, although increasing

\section{Biomed Central}


evidence points towards a role for genetic variation in the host's immune response [5]. In particular, recent insights from the study of animal models, rare human primary immunodeficiency states, and population-based genetic epidemiology have focused attention on the control of the proinflammatory transcription factor NF- $\kappa \mathrm{B}$ in the development of IPD [5-10].

NF- $\kappa \mathrm{B}$ plays a key regulatory role in a diverse array of cellular processes, including innate and adaptive immune responses $[11,12]$. In unstimulated cells, NF- $\kappa \mathrm{B}$ transcription factor subunits are prevented from binding DNA through associations with the inhibitor of NF- $\kappa$ B $(\mathrm{I} \kappa \mathrm{B})$ protein family. Stimulation of a variety of immune receptors (including Toll-like receptors, T-cell and Bcell antigen receptors and members of the IL-1 and TNF receptor superfamilies) leads to phosphorylation and degradation of the $\mathrm{I} \kappa \mathrm{B}$ inhibitors and release of NF$\kappa \mathrm{B}$, which induces transcription of proinflammatory target genes $[11,12]$. Genes that are activated by NF- $\kappa \mathrm{B}$ include those encoding cytokines (for example, IL-1, IL2, IL-6, TNF $\alpha$ ) and chemokines (for example, IL-8, RANTES), as well as acute phase response proteins, adhesion molecules, antimicrobial peptides and inducible enzymes $[11,12]$.

Members of the $\mathrm{I} \kappa \mathrm{B}$ family are characterised by multiple ankyrin repeats and can be subdivided into the socalled classical $\mathrm{I} \kappa \mathrm{Bs}(\mathrm{I} \kappa \mathrm{B}-\alpha, \mathrm{I} \kappa \mathrm{B}-\beta, \mathrm{I} \kappa \mathrm{B}-\varepsilon)$, unusual $\mathrm{I} \kappa \mathrm{Bs}$ ( $\mathrm{I} \kappa \mathrm{B}-\mathrm{R}, \mathrm{I} \kappa \mathrm{B}-\zeta, \mathrm{I} \kappa \mathrm{B}-\mathrm{L}, \mathrm{Bcl}-3)$, and $\mathrm{NF}-\kappa \mathrm{B}$ precursors $[12,13]$. Of these, the least well studied is $\mathrm{I} \kappa \mathrm{B}-\mathrm{R}(\mathrm{I} \kappa \mathrm{B}-$ related), encoded by the gene NFKBIL2. The gene was first cloned in 1995 from human lung alveolar epithelial cells, and a modified sequence was published in 2000 $[14,15]$. The gene contains only three ankyrin-repeat motifs, fewer than other $\mathrm{I} \kappa \mathrm{B}$ members, and its exons have a more complicated structure than that seen in other $\mathrm{I} \kappa \mathrm{Bs}$; overall there is only weak homology between $\mathrm{I} \kappa \mathrm{B}-\mathrm{R}$ and other $\mathrm{I} \kappa \mathrm{B}$ proteins, leading to the suggestion that $\mathrm{I} \kappa \mathrm{B}-\mathrm{R}$ may in fact not be a member of the $\mathrm{I} \kappa \mathrm{B}$ family [15]. There is evidence, however, to support an interaction of $\mathrm{I} \kappa \mathrm{B}-\mathrm{R}$ with NF- $\kappa \mathrm{B}$. I $\kappa \mathrm{B}-\mathrm{R}$ was first shown to inhibit DNA binding by NF- $\kappa \mathrm{B}$ in electrophoretic mobility shift assays [14], and overexpression of NFKBIL 2 in lung alveolar epithelial cells was subsequently reported to significantly upregulate the production of RANTES (now renamed chemokine C-C motif ligand 5 (CCL5)) protein following stimulation with TNF $\alpha$ or IL-1 $\alpha$, although it had no effect on other NF$\kappa \mathrm{B}$-responsive chemokines such as IL-8 [16].

Increasing evidence supports a central role for the control of NF- $\kappa \mathrm{B}$ in susceptibility to severe infectious disease in humans. A mutation in the gene NFKBIA encoding the classical inhibitor $\mathrm{I} \kappa \mathrm{B}-\alpha$ has been described in two patients with primary immunodeficiency [8]. In addition, population-based case-control studies of IPD have reported associations with polymorphisms in the $\mathrm{I} \kappa \mathrm{B}$-encoding genes NFKBIA and NFKBIZ $[9,10]$. These findings raise the possibility that variation in additional $\mathrm{I} \kappa \mathrm{Bs}$ such as $\mathrm{I} \kappa \mathrm{B}-\mathrm{R}$ may also contribute to IPD susceptibility. No functional or diseaseassociated polymorphisms have previously been reported in NFKBIL2, however. To investigate this further we studied the frequencies of NFKBIL2 polymorphisms in individuals with IPD and healthy controls of both European and African descent.

\section{Materials and methods \\ Sample information}

The UK Caucasian IPD sample collection has been previously described [17]. Blood samples were collected on diagnosis from all hospitalised patients with microbiologically-proven IPD (defined by the isolation of $S$. pneumoniae from a normally sterile site, most commonly blood) as part of an enhanced active surveillance programme between June 1995 and May 2001 in three hospitals in Oxfordshire, UK: John Radcliffe Hospital, Horton General Hospital, and Wycombe General Hospital. There were no exclusion criteria for the study. DNA samples were available for study from 275 patients. Clinical details, including age, gender, clinical presentation and the presence of underlying risk factors, were recorded. During the study, Oxfordshire was a region of very low HIV prevalence and HIV testing was not routinely performed. Frequencies of initial clinical presentation were as follows: pneumonia 69\%, isolated bacteraemia $15 \%$, meningitis $11 \%$, and other presentations $5 \%$. The mean age of the patients was 58 years, ranging from 0 to 94 years; $50 \%$ were male. Pneumococcal serotypes were identified using polyclonal rabbit antisera (Statens Seruminstitut, Copenhagen, Denmark). The distribution of serotypes was very similar to that of previous UK studies, with serotype 14 being the commonest.

The control group comprised a combination of 163 UK healthy adult blood donors and 570 cord blood samples. For the cord samples, blood was collected anonymously from the discarded umbilical cords of healthy neonates born at the John Radcliffe Hospital, Oxford, UK, as previously described [17]. Examination of microsatellite markers excluded contamination with maternal DNA. The use of DNA from cord blood samples is intended to reveal background population allele frequencies; recent large-scale genotyping of a UK birth cohort control group for association studies of multiple disease phenotypes has confirmed the validity of such an approach [18]. The mean age of the adult blood donors was 38 years, and $50 \%$ were male; $54 \%$ of the cord blood donors were male. Individuals of non-European ancestry were excluded from cases and controls. The 
study was approved by the Oxford Local Research Ethics Committee and informed consent was obtained from all participants.

The Kenyan bacteraemia case-control collection has also been previously described [19]. Kenyan children (<13 years old) with bacteraemia were recruited from Kilifi District hospital between 1998 and 2002. The 687 bacteraemic cases comprised patients with isolated Gram-positive and Gram-negative infections, diagnosed using standard blood culture techniques. The most frequent organisms isolated were S. pneumoniae (25\%), non-Typhi Salmonella species (16\%), Haemophilus influenzae (14\%), and Escherichia coli (8\%), as well as other less common bacteria. The 550 community controls were individually matched to a subset of the cases on the basis of time (recruited within 14 days), location of homestead, age, and sex. Only children with complete data for HIV, malnutrition, and malaria status were included in the analysis. Ethical approval for the study was given by the Kenya Medical Research Institute National Scientific Steering and Research Committees and informed consent was obtained from all participants.

\section{Genotyping techniques}

DNA extraction from blood was performed using Nucleon II kits (Scotlab Bioscience, Buckingham, UK). Polymorphisms within NFKBIL2 were selected from the dbSNP and ensembl databases on the basis of their probable functionality $[20,21]$, as well as to provide an overview of linkage disequilibrium (LD) across the gene and flanking regions. Genotyping was performed using the Sequenom Mass-Array $\left.{ }^{(}\right)$MALDI-TOF primer extension assay [22]; primer sequences are listed in Table 1. A touch-down PCR protocol was used, with cycling conditions as follows: $95^{\circ} \mathrm{C}$ for 15 minutes; $94^{\circ} \mathrm{C}$ for $20 \mathrm{sec}-$ onds; $65^{\circ} \mathrm{C}$ for 30 seconds; $72^{\circ} \mathrm{C}$ for 30 seconds; steps 2 to 4 repeated for five cycles; $94^{\circ} \mathrm{C}$ for 20 seconds; $58^{\circ} \mathrm{C}$ for 30 seconds; $72^{\circ} \mathrm{C}$ for 30 seconds; steps 5 to 7 repeated for five cycles; $94^{\circ} \mathrm{C}$ for 20 seconds; $53^{\circ} \mathrm{C}$ for 30 seconds; $72^{\circ} \mathrm{C}$ for 30 seconds; steps 8 to 10 repeated for 38 cycles; and final extension at $72^{\circ} \mathrm{C}$ for 3 minutes. Each genotyping plate contained a mixture of case and control samples.

General PCR conditions for amplifying products prior to sequencing were as follows: $95^{\circ} \mathrm{C}$ for 15 minutes, and then 40 cycles of $95^{\circ} \mathrm{C}$ for 30 seconds, 55 to $65^{\circ} \mathrm{C}$ for 30 seconds, and $72^{\circ} \mathrm{C}$ for 60 seconds, followed by $72^{\circ} \mathrm{C}$ for 5 minutes. Direct sequencing was performed using BigDye v3.1 terminator mix (Applied Biosystems, Foster City, CA, USA) followed by ethanol precipitation. Plates were run on an ABI 3700 capillary sequencer and sequence analysis was performed with the Lasergene DNAstar package using SeqMan software (DNASTAR
Inc., Madison, WI, USA). Primer sequences are listed in Table 2.

\section{Statistical analysis}

Statistical analysis of genotype associations and logistic regression was performed using the program SPSS v16.0 (SPSS, Inc., Chicago, IL, USA). Two-tailed tests of significance were used for all analysis. Uncorrected $P$ values are presented throughout; appropriate significance thresholds in the setting of multiple testing are described in the Discussion. Tarone's homogeneity of odds ratio (OR) testing was performed to compare ORs between study groups; if appropriate, study groups were combined and stratified using Mantel-Haenszel testing (SPSS v16.0). Analysis of LD was performed using the Haploview v4.1 program [23]. Haplotype blocks were defined as regions demonstrating strong evidence of historical recombination between $<5 \%$ of SNP-pair comparisons [24]. All control genotype distributions were in Hardy-Weinberg equilibrium.

\section{Results}

The initial genotyping approach utilised the UK Caucasian IPD case-control study group and focused on three SNPs within NFKBIL2: rs760477, rs2306384, and rs4082353. Whilst both rs760477 and rs4082353 are intronic, rs2306384 encodes a serine/glycine substitution at position 334 of the $I \kappa B-R$ protein. Each of these SNPs was found to be common in Europeans (minor allele frequencies approaching 50\%) and to associate with susceptibility to IPD ( $P=0.002$ to 0.007 ; Table 3 ). Logistic regression analysis demonstrated no effect of age, comorbidity or gender on genotype. Genotyping was then extended to flanking SNPs in both directions spanning a $74 \mathrm{~kb}$ region across chromosome $8 \mathrm{q} 24.3$ to delineate the extent of LD and disease association. Twelve SNPs were found to be either nonpolymorphic or extremely rare (minor allele frequency <0.01) and could not be analysed further (Table 3 ). A further six SNPs were polymorphic, of which two associated with IPD susceptibility at the 0.05 significance level and one trended towards association $(P=0.035$ to 0.085 ; Table 3). In each case the minor alleles were again found to be common, and the direction of association was one of heterozygote protection against IPD (Table 3).

The extent of LD between SNPs was next assessed. All five IPD-associated SNPs were found to be located within a $20 \mathrm{~kb}$ block of strong LD in this European population (Figure 1). The absence of association with SNPs outside this block suggests that the causative locus is indeed localised to this $20 \mathrm{~kb}$ region, which contains the entire NFKBIL2 gene as well as the neighbouring gene in a $3^{\prime}$ direction, vacuolar protein sorting 28 (VPS28). This extensive LD presents a considerable 


\begin{tabular}{|c|c|c|}
\hline Polymorphism & PCR primer sequences & Extension primer sequences \\
\hline \multirow[t]{2}{*}{ rs10448143 } & ACGTTGGATGGGAACTGGAGCACGGGCTT & CACGGGCTTCCCGTGGC \\
\hline & ACGTTGGATGAAGATGTCTCAGGGTCTTGG & \\
\hline \multirow[t]{2}{*}{ rs2170096 } & ACGTTGGATGACTCCCAACCTCAGGTCATC & GCTGGGATCACAGGCGTGAG \\
\hline & ACGTTGGATGAGAAATTGGGTTGTCAGCCG & \\
\hline \multirow[t]{2}{*}{ rs4925858 } & ACGTTGGATGTGCAGGAGGCAGGAAATCCA & GCAGGCCTGGGTGTGAG \\
\hline & ACGTTGGATGATGCTITGGATGGGCAAGGG & \\
\hline \multirow[t]{2}{*}{ rs760477 } & ACGTTGGATGAAAGGGAGGGCTCCAGAAGAC & TCCAGAAGACGGGATTGCCCAA \\
\hline & ACGTTGGATGGCGTTTTCTGCCTCCTGAAC & \\
\hline \multirow[t]{2}{*}{ rs2306384 } & ACGTTGGATGGGAAATGCAAGGTGCCGCTG & TGCCGCTGGCCCTCACCGC \\
\hline & ACGTTGGATGAGCCACAGCGGAGAGCGAAG & \\
\hline \multirow[t]{2}{*}{ rs4082353 } & ACGTTGGATGTAGTCTGCTCTGAAGGTTGG & TGGAGAGACCAGAGGCAGA \\
\hline & ACGTTGGATGTGATCCCAGCTCCTAAAACC & \\
\hline \multirow[t]{2}{*}{ rs2272658 } & ACGTTGGATGAACTGTTCCTGAGGCACTCC & GAGGCACTCCAGGATGGAGC \\
\hline & ACGTTGGATGTAGAGCCCAGAGTGCTACCC & \\
\hline \multirow[t]{2}{*}{ rs13258200 } & ACGTTGGATGAAAGTGACTGGCAGCTTCTG & CCTCCTAGGGCTCTGAGTTCCTGC \\
\hline & ACGTTGGATGTGGTGGTGTTGGTGTAGTTG & \\
\hline \multirow[t]{2}{*}{ rs4380978 } & ACGTTGGATGCAAAGCCTTCCAGTTTGGAC & AGATGAAACGGGTGCCCC \\
\hline & ACGTTGGATGCTGCACACACTCACCATAAG & \\
\hline
\end{tabular}

challenge, however, in identifying the IPD-causative polymorphism. The extent of LD in African populations is typically shorter than in Europeans [24], and this can be advantageous when attempting to fine map an extensive region of disease association. With this in mind, all nine polymorphisms were then genotyped in the Kenyan bacteraemia case-control study (Tables 4 and 5). The LD was noted to be much less extensive in this African population, and no haplotype blocks were predicted by the Gabriel algorithm within the region studied (Figure 2).

Two of the NFKBIL2 SNPs genotyped were found to be significantly associated with susceptibility to Grampositive and pneumococcal bacteraemia in Kenyan children (rs4925858 and rs760477; Table 6). In each case the direction of association was of heterozygote protection, the same genetic model as that observed in the UK Caucasian study. Logistic regression analysis demonstrated no effect of age, comorbidity, HIV infection or gender on genotype. Comparison of ORs for rs4925858 and rs760477 did not demonstrate any evidence of heterogeneity between the UK and Kenyan case-control groups for either SNP. The strongest association was with rs760477; on combining and stratifying the UK and Kenyan study groups, heterozygosity at rs760477 was associated with significant protection against invasive bacterial disease overall (IPD in the UK study and overall bacteraemia in the Kenyan study; Mantel-Haenszel $2 \times 2 \chi^{2}=18.567, P=1.6 \times 10^{-5}, \mathrm{OR}=0.66,95 \%$ confidence interval for OR $=0.55$ to 0.80 ) and against invasive pneumococcal disease specifically (Mantel-Haenszel $2 \times 2 \chi^{2}=11.797, P=0.0006$, OR $=0.67,95 \%$ confidence interval for $\mathrm{OR}=0.53$ to 0.84 ). Heterozygosity at the neighbouring SNP rs4925858 was also found to be protective against both invasive bacterial disease overall (Mantel-Haenszel $2 \times 2 \chi^{2}=8.610, P=0.003$, OR = $0.76,95 \%$ confidence interval for $\mathrm{OR}=0.63$ to 0.91 ) and IPD (Mantel-Haenszel $2 \times 2 \chi^{2}=9.104, P=0.003$, OR $=0.70,95 \%$ confidence interval for $\mathrm{OR}=0.55$ to 0.88 ). None of the SNPs appeared to be associated with

Table 2 Primer sequences used for direct sequencing

\begin{tabular}{lll}
\hline Name & Forward primer sequence & Reverse primer sequence \\
\hline NFKBIL2_prom & CGTCAGTCTATCTGGACAC & CTCGCGCTCCAGGCTCATGCTC \\
NFKBIL2_ex1_2 & GAGCATGAGCCTGGAGCGCGAG & CAAGGCTGCGTCAGGTCAGGTG \\
NFKBIL2_int2 & CACCTGACCTGACGCAGCCTTG & CAGTGGCTTCACGCTGTATGCAGC \\
NFKBIL2_ex3 & GCTGCATACAGCGTGAAGCCACTG & GGATAAAGAGCTGACGATCTCCAG \\
NFKBIL2_ex4 & CTGGAGATCGTCAGCTCTTTATCC & TACTTCCTCCAGGAACAAG \\
NFKBIL2_ex5_6 & CTTGTCCTGGAGGAAGTA & GAGCCCTGTACACACCTG \\
\hline
\end{tabular}


Table 3 NFKBIL2 and flanking gene polymorphism genotype frequencies in European individuals with IPD and controls

\begin{tabular}{|c|c|c|c|c|c|c|c|}
\hline \multirow[t]{2}{*}{$\begin{array}{l}\text { Polymorphism/location }{ }^{\text {a }} \text { (major/minor } \\
\text { allele) }\end{array}$} & \multirow[t]{2}{*}{ Status } & \multicolumn{3}{|c|}{ Genotype distribution $^{\mathbf{b}}$} & \multirow{2}{*}{$\begin{array}{l}\text { Genotypic } 3 \times 2 \\
\text { chi-square }(P \\
\text { value })\end{array}$} & \multicolumn{2}{|c|}{$\begin{array}{l}\text { Heterozygote protection } \\
\text { model }^{c}\end{array}$} \\
\hline & & $\overline{\mathrm{AA}}$ & $\mathrm{Aa}$ & aа & & OR $(95 \% \mathrm{Cl})$ & $P$ value $^{d}$ \\
\hline \multirow[t]{2}{*}{ rs10448143, -5,224, 5' upstream (C/T) } & Control & $203(57.7 \%)$ & $126(35.8 \%)$ & $23(6.5 \%)$ & $1.245(0.537)$ & 1.17 (0.79 to 1.72$)$ & 0.425 \\
\hline & IPD & $88(56.1 \%)$ & $62(39.5 \%)$ & $7(4.5 \%)$ & & & \\
\hline \multirow[t]{2}{*}{ rs2170096, -4,368, 5' upstream (C/G) } & Control & $164(24.3 \%)$ & $349(51.7 \%)$ & $162(24.0 \%)$ & $4.927(0.085)$ & 0.71 (0.51 to 0.99$)$ & 0.036 \\
\hline & IPD & $53(26.4 \%)$ & 87 (43.3\%) & $61(30.3 \%)$ & & & \\
\hline \multirow[t]{2}{*}{ rs4925858, $-3,771,5^{\prime}$ upstream (G/A) } & Control & $185(27.1 \%)$ & $360(52.7 \%)$ & $138(20.2 \%)$ & $6.664(\mathbf{0 . 0 3 6})$ & 0.69 (0.50 to 0.95$)$ & 0.016 \\
\hline & IPD & $66(29.6 \%)$ & 97 (43.5\%) & $60(26.9 \%)$ & & & \\
\hline \multirow[t]{2}{*}{ rs760477, -263, NFKBIL2 intron 4 (C/T) } & Control & $188(26.3 \%)$ & $370(51.7 \%)$ & $158(22.1 \%)$ & $9.810(\mathbf{0 . 0 0 7})$ & 0.64 (0.48 to 0.85$)$ & 0.002 \\
\hline & IPD & $82(31.3 \%)$ & $106(40.5 \%)$ & $74(28.2 \%)$ & & & \\
\hline \multirow{2}{*}{$\begin{array}{l}\text { rs2306384, +2,754, Ser/Gly, NFKBIL2 exon } \\
11 \text { (A/G) }\end{array}$} & Control & $158(24.6 \%)$ & $336(52.4 \%)$ & $147(22.9 \%)$ & $12.329(\mathbf{0 . 0 0 2})$ & 0.61 (0.45 to 0.83$)$ & 0.001 \\
\hline & IPD & $67(27.0 \%)$ & $100(40.3 \%)$ & $81(32.7 \%)$ & & & \\
\hline \multirow[t]{2}{*}{ rs4082353, +12,589, NFKBIL2 intron 25 (G/T) } & Control & $175(27.2 \%)$ & $327(50.8 \%)$ & $142(22.0 \%)$ & $9.932(\mathbf{0 . 0 0 7})$ & $0.66(0.49$ to 0.89$)$ & 0.005 \\
\hline & IPD & $70(28.6 \%)$ & $99(40.4 \%)$ & $76(31.0 \%)$ & & & \\
\hline \multirow[t]{2}{*}{ rs2272658, +16,899, VPS28 intron 4 (C/T) } & Control & $156(24.6 \%)$ & $330(52.1 \%)$ & $147(23.2 \%)$ & $6.684(\mathbf{0 . 0 3 5})$ & 0.68 (0.49 to 0.95$)$ & 0.023 \\
\hline & IPD & $47(25.7 \%)$ & $78(42.6 \%)$ & $58(31.7 \%)$ & & & \\
\hline \multirow[t]{2}{*}{ rs13258200, +36,964, CPSF1 intron 2 (A/C) } & Control & $258(39.2 \%)$ & $317(48.1 \%)$ & $84(12.7 \%)$ & $0.364(0.833)$ & $0.95(0.72$ to 1.26$)$ & 0.739 \\
\hline & IPD & $107(38.9 \%)$ & $129(46.9 \%)$ & 39 (14.2\%) & & & \\
\hline \multirow[t]{2}{*}{ rs4380978, +68,695, ADCK5 intron 1 (G/C) } & Control & $212(31.7 \%)$ & $347(51.9 \%)$ & $110(16.4 \%)$ & $0.227(0.893)$ & $0.94(0.70$ to 1.26$)$ & 0.696 \\
\hline & IPD & $78(32.0 \%)$ & $123(50.4 \%)$ & $43(17.6 \%)$ & & & \\
\hline
\end{tabular}

VPS28, vacuolar protein sorting 28; CPSF1, cleavage and polyadenylation-specific factor 1; ADCK5, aarF domain-containing kinase 5; OR, odds ratio; Cl, confidence interval; IPD, invasive pneumococcal disease. The following NFKBIL2 SNPs were nonpolymorphic or very rare (minor allele frequency <0.01) in the UK Caucasian population studied: rs7459910; rs2306383; rs4448319; rs3802163; rs4925856; rs2242264; rs2620660; rs741970; rs4925857; rs6985339; rs2928378; rs12677973. ${ }^{a}$ SNP positions listed are relative to the start of translation (in exon 5). ${ }^{\mathrm{b}}$ Number of individuals (\%). ' Comparison of heterozygotes [Aa] with homozygotes [AA + aa].

$\mathrm{d}_{2} \times 2$ chi-squared comparison, one degree of freedom. $P$ values below 0.05 are highlighted in bold.

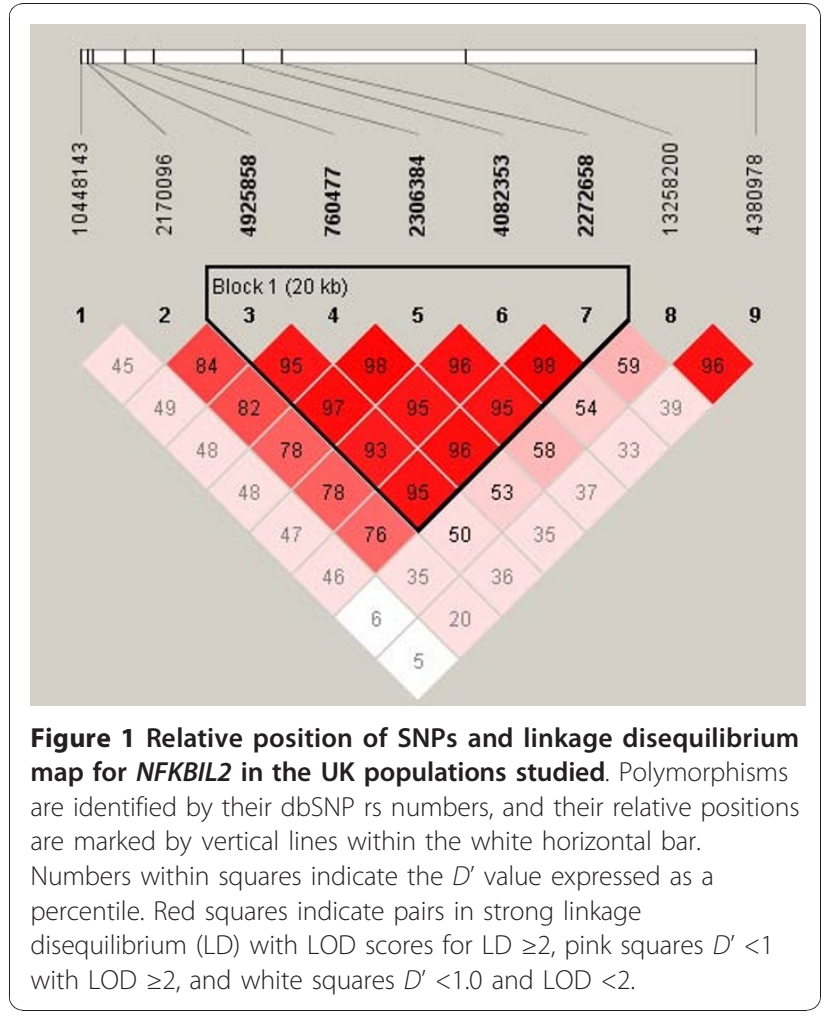

outcome of bacteraemia in these groups (data not shown), although the number of individuals in the poor outcome groups was small (mortality rates were 10\% in the UK IPD study and $28 \%$ in the Kenyan study), resulting in a lack of power to examine possible effects of genotype on mortality.

The SNP rs760477 is located within the fourth intron of NFKBIL2. The first seven exons of NFKBIL2, which surround rs760477, were then sequenced in 48 Kenyan individuals in an attempt to identify novel and potentially functional variants. The sequencing covered a 3,100 base pair region extending in a 3' direction from 780 base pairs prior to the start of transcription in exon 1. No novel exonic polymorphisms were identified with the exception of a synonymous polymorphism encoding asparagine at position 23 of the $\mathrm{I} \kappa \mathrm{B}-\mathrm{R}$ protein, which has subsequently been listed on databases and named rs35913924. This SNP was then genotyped in the Kenyan cases and controls: the mutant allele was found to be uncommon (allele frequency 3.6\%), and no association with disease was identified $\left(3 \times 2 \chi^{2}=0.37, P=\right.$ $0.83)$. The sequencing also confirmed the genotyping accuracy of rs760477 (100\% concordance between direct sequencing and Sequenom genotyping). 
Table 4 NFKBIL2 and flanking gene polymorphism allele frequencies: European IPD and African bacteraemia case-control studies

\begin{tabular}{|c|c|c|c|c|}
\hline \multirow{2}{*}{$\begin{array}{l}\text { Polymorphism/ } \\
\text { location }\end{array}$} & \multicolumn{2}{|c|}{ UK Caucasian study } & \multicolumn{2}{|c|}{ Kenyan study } \\
\hline & $\begin{array}{l}\text { Minor allele } \\
\text { frequency } \\
\text { (\%) }\end{array}$ & $P$ value $^{a}$ & $\begin{array}{l}\text { Minor allele } \\
\text { frequency } \\
(\%)\end{array}$ & $P$ value $^{a}$ \\
\hline $\begin{array}{l}\text { rs10448143, } \\
-5,224\end{array}$ & 24.3 & 0.537 & 4.7 & $0.250^{b}$ \\
\hline rs2170096, -4,368 & 49.6 & 0.085 & 38.2 & 0.145 \\
\hline rs4925858, -3,771 & 47.1 & 0.036 & 30.7 & 0.128 \\
\hline rs760477, -263 & 48.1 & 0.007 & 25.7 & 0.009 \\
\hline rs2306384, +2,754 & 49.8 & 0.002 & 33.5 & 0.427 \\
\hline $\begin{array}{l}r s 4082353 \\
+12,589\end{array}$ & 48.5 & 0.007 & 33.4 & 0.857 \\
\hline $\begin{array}{l}\text { rs2272658, } \\
+16,899\end{array}$ & 49.9 & 0.035 & 36.7 & 0.927 \\
\hline $\begin{array}{l}\text { rs13258200, } \\
+36,964\end{array}$ & 37.0 & 0.833 & 40.2 & 0.801 \\
\hline $\begin{array}{l}\text { rs } 4380978, \\
+68,695\end{array}$ & 42.5 & 0.893 & 32.6 & 0.648 \\
\hline
\end{tabular}

${ }^{\text {a }} P$ values are derived from $3 \times 2$ chi-squared comparisons of genotypes (two degrees of freedom). ${ }^{b}$ Fisher's exact test (two-tailed). $P$ values below 0.05 are highlighted in bold.

\section{Discussion}

In this study we demonstrate associations between common NFKBIL2 polymorphisms and susceptibility to IPD in UK Caucasian and Kenyan individuals. Important causes of false positive associations in genetic studies are a failure to adjust significance levels when multiple polymorphisms have been analysed, and confounding by population substructure. Nine polymorphisms were analysed, and applying a Bonferroni correction results in a threshold significance level of 0.0055 , rather than 0.05 . With this corrected significance level, rs760477, rs2306384 and rs4082353 in the UK population remain associated with protection against IPD. The Bonferroni correction, however, assumes that markers are independent, whereas many of the polymorphisms studied here are in strong or complete LD in UK individuals and are therefore not truly independent from each other. Applying instead a correction based on the total number of LD blocks and singleton (not part of a LD block) polymorphisms, five independent tests were performed in the UK study group, suggesting a threshold $P$ value of
0.01 for statistical significance. The extent of LD was much less in Kenyan individuals, and as a result no LD blocks were predicted (Figure 2). In this setting, none of the polymorphisms in the Kenyan study reaches the Bonferroni-corrected $P$ value threshold of 0.0055 to declare significance. Nevertheless, given the observed association between NFKBIL2 SNPs and IPD in UK individuals, the $a$ priori probability that such a SNP protects against IPD in the Kenyan population might be expected to be higher than for a random marker, and in this situation the Bonferroni adjustment may be overly stringent. It is also noteworthy that the SNPs rs 4925858 and rs760477 trend or associate in the same direction (heterozygote protection) in the Kenyan study as that observed in the UK study group, and combined analysis of the UK and Kenyan study groups using the MantelHaenszel test further strengthens the association between NFKBIL2rs760477 and IPD.

Addressing the possibility of population substructure, recent analysis of an extensive dataset of over 15,000 individuals from Britain demonstrated remarkably little evidence of geographic population differentiation within British Caucasians [18], and moreover our cases and controls are from a relatively restricted geographic area (Oxfordshire). Furthermore, the observation of a trend towards heterozygote protection against IPD in a second, independent study of African individuals provides additional support for an association between NFKBIL2 polymorphisms and pneumococcal disease. The results of the Kenyan study additionally suggest that the NFKBIL2 association may be with bacteraemia overall, rather than a specific effect on pneumococcal susceptibility, although this finding requires replication.

In general, a possible disadvantage for the use of the Kenyan samples as a replication study group is their different ethnic background: a lack of replication may reflect true ethnic heterogeneity in pneumococcal disease susceptibility. On the other hand, the study of a second population with differing patterns of LD may aid fine-mapping of associations within regions of strong $\mathrm{LD}$, and it has been suggested that the demonstration of genetic associations with disease susceptibility across different populations is perhaps of even more value than the identification of population-specific effects [25]. The IPD-associated polymorphisms in the UK Caucasian study span a distance of $20 \mathrm{~kb}$ including the genes NFKBIL2 and VPS28. On the basis of these results alone it is not possible to further localise the disease association within this region, although the associations within the Kenyan study group appear to focus the association within NFKBIL2. Despite the use of such a transethnic mapping approach, the functional variant in NFKBIL2 that is responsible for the association with IPD remains unknown. Perhaps the most probable functional variant 
Table 5 NFKBIL2 and flanking gene polymorphism genotype frequencies in Kenyan individuals with bacteraemia and controls

\begin{tabular}{|c|c|c|c|c|c|c|c|}
\hline \multirow[t]{2}{*}{$\begin{array}{l}\text { Polymorphism/location }{ }^{\text {a }} \text { (major/ } \\
\text { minor allele) }\end{array}$} & \multirow[t]{2}{*}{ Status } & \multicolumn{3}{|c|}{ Genotype distribution $^{\mathrm{b}}$} & \multirow{2}{*}{$\begin{array}{l}\text { Genotypic } 3 \times 2 \\
\text { chi-square } \\
(P \text { value })\end{array}$} & \multicolumn{2}{|c|}{$\begin{array}{l}\text { Heterozygote protection } \\
\text { model }^{\mathrm{c}}\end{array}$} \\
\hline & & $\mathrm{AA}$ & $\mathrm{Aa}$ & aа & & OR $(95 \% \mathrm{Cl})$ & $P$ value \\
\hline \multirow[t]{2}{*}{ rs10448143, $-5,224,5^{\prime}$ upstream (C/T) } & Control & $433(89.6 \%)$ & $50(10.4 \%)$ & $0(0 \%)$ & $0.250^{e}$ & $0.78(0.52$ to 1.17$)$ & 0.226 \\
\hline & Bacteraemia & $598(91.4 \%)$ & $54(8.3 \%)$ & $2(0.3 \%)$ & & & \\
\hline \multirow[t]{2}{*}{ rs2170096, $-4,368,5^{\prime}$ upstream (C/G) } & Control & $128(38.7 \%)$ & $136(41.1 \%)$ & $67(20.2 \%)$ & 0.145 & $0.93(0.66$ to 1.31$)$ & 0.672 \\
\hline & Bacteraemia & $107(45.7 \%)$ & 92 (39.3\%) & $35(15.0 \%)$ & & & \\
\hline \multirow[t]{2}{*}{ rs4925858, $-3,771,5^{\prime}$ upstream (G/A) } & Control & $255(46.4 \%)$ & $247(44.9 \%)$ & $48(8.7 \%)$ & 0.128 & $0.80(0.64$ to 1.00$)$ & 0.053 \\
\hline & Bacteraemia & $343(49.9 \%)$ & $271(39.4 \%)$ & $73(10.6 \%)$ & & & \\
\hline \multirow[t]{2}{*}{ rs760477, -263, NFKBIL2 intron 4 (C/T) } & Control & $262(53.0 \%)$ & $192(38.9 \%)$ & $40(8.1 \%)$ & 0.009 & 0.68 (0.53 to 0.87$)$ & 0.002 \\
\hline & Bacteraemia & $403(60.6 \%)$ & $201(30.2 \%)$ & $61(9.2 \%)$ & & & \\
\hline \multirow{2}{*}{$\begin{array}{l}\text { rs2306384, +2,754, Ser/Gly, NFKBIL2 } \\
\text { exon } 11(\mathrm{~A} / \mathrm{G})\end{array}$} & Control & $238(45.0 \%)$ & $224(42.3 \%)$ & $67(12.7 \%)$ & 0.427 & 0.84 (0.65 to 1.09$)$ & 0.195 \\
\hline & Bacteraemia & $214(47.9 \%)$ & $171(38.3 \%)$ & $62(13.8 \%)$ & & & \\
\hline \multirow{2}{*}{$\begin{array}{l}\text { rs } 4082353,+12,589, \text { NFKBIL2 intron } \\
25(\mathrm{G} / \mathrm{T})\end{array}$} & Control & $160(47.6 \%)$ & $132(39.3 \%)$ & $44(13.1 \%)$ & 0.857 & 1.05 (0.75 to 1.47$)$ & 0.785 \\
\hline & Bacteraemia & $109(45.4 \%)$ & $97(40.4 \%)$ & $34(14.2 \%)$ & & & \\
\hline \multirow[t]{2}{*}{ rs2272658, +16,899, VPS28 intron 4 (C/T) } & Control & $135(40.9 \%)$ & $145(43.9 \%)$ & $50(15.2 \%)$ & 0.927 & 0.96 (0.69 to 1.33$)$ & 0.791 \\
\hline & Bacteraemia & $113(42.5 \%)$ & $114(42.9 \%)$ & $39(14.7 \%)$ & & & \\
\hline \multirow{2}{*}{$\begin{array}{l}\text { rs13258200, +36,964, CPSF1 intron } \\
2(\mathrm{~A} / \mathrm{C})\end{array}$} & Control & $212(37.7 \%)$ & $245(43.6 \%)$ & $105(18.7 \%)$ & 0.801 & $1.06(0.85$ to 1.33$)$ & 0.601 \\
\hline & Bacteraemia & $259(37.5 \%)$ & $311(45.1 \%)$ & $120(17.4 \%)$ & & & \\
\hline \multirow{2}{*}{ rs4380978, +68,695, ADCK5 intron 1 (G/C) } & Control & $246(45.6 \%)$ & $231(42.8 \%)$ & $63(11.6 \%)$ & 0.648 & $0.90(0.71$ to 1.13$)$ & 0.352 \\
\hline & Bacteraemia & $329(47.7 \%)$ & $277(40.1 \%)$ & $84(12.2 \%)$ & & & \\
\hline
\end{tabular}

VPS28, vacuolar protein sorting 28; CPSF1, cleavage and polyadenylation-specific factor 1; $A D C K 5$, aarF domain-containing kinase 5; OR, odds ratio; Cl, confidence interval; IPD, invasive pneumococcal disease. ${ }^{a} \mathrm{SNP}$ positions listed are relative to the start of translation (in exon 5). ${ }^{b} \mathrm{Number}$ of individuals (\%). ${ }^{\mathrm{C}} \mathrm{Comparison}$ of

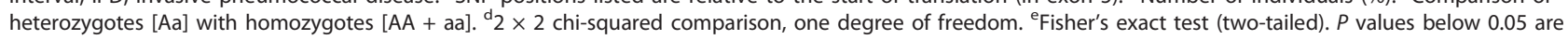
highlighted in bold.

within NFKBIL2 is the coding change rs2306384, but it is noteworthy that this association did not replicate in the Kenyan study group. The SNP rs760477 is located within intron 4 and is unlikely itself to exert a functional effect, and no disease-associated polymorphisms were identified in the surrounding exons. The polymorphism rs4925858 is located 1,650 base pairs before the transcription start, and could conceivably affect a regulatory region such as a promoter, enhancer or silencer.

The mechanism by which $\mathrm{I} \kappa \mathrm{B}-\mathrm{R}$ variation influences susceptibility to IPD is also unclear. One possibility is through an effect on CCL5 expression, which has been reported to be upregulated in lung epithelial cells following overexpression of $\mathrm{I} \kappa \mathrm{B}-\mathrm{R}$ [16]. The mechanism behind this cytokine-induced upregulation appears to be sequestering of transcriptionally repressive NF- $\kappa \mathrm{B}$ p 50 homodimer subunits by $\mathrm{I} \kappa \mathrm{B}-\mathrm{R}$, thereby facilitating NF$\kappa \mathrm{B}$-mediated gene transcription of CCL5 [16]. Both CCL 5 mRNA and protein expression are stimulated following exposure to the pneumococcal proteins pneumolysin and choline-binding protein A in dendritic cells, and furthermore CCL5 blockade during pneumococcal carriage in mice is associated with an attenuated immune response and greater transition to lethal pneumonia [26,27]. Further research is required to examine the possible role of $\mathrm{I} \kappa \mathrm{B}-\mathrm{R}$ in regulation of CCL5 during pneumococcal disease, and indeed to identify the cellular roles of $\mathrm{I} \kappa \mathrm{B}-\mathrm{R}$ more generally. This protein has been relatively neglected compared with the extensive literature on other $\mathrm{I} \kappa \mathrm{Bs}$, and it remains unclear for example which specific NF- $\kappa$ B dimers interact with $I \kappa B-R$ $[14,16]$.

The direction of association with disease is noteworthy: heterozygosity was associated with protection against IPD in each study population. The finding of heterozygote protection is unusual in genetic disease association studies, but is well described in the study of human infectious disease genetic susceptibility - examples include sickle cell trait and malaria, prion protein gene variation and spongiform encephalopathy, and human leukocyte antigen and HIV/AIDS disease progression [28-30]. More recently, heterozygosity at loci within both the Toll-like receptor adaptor protein Mal/ TIRAP and NFKBIZ have been found to associate with 


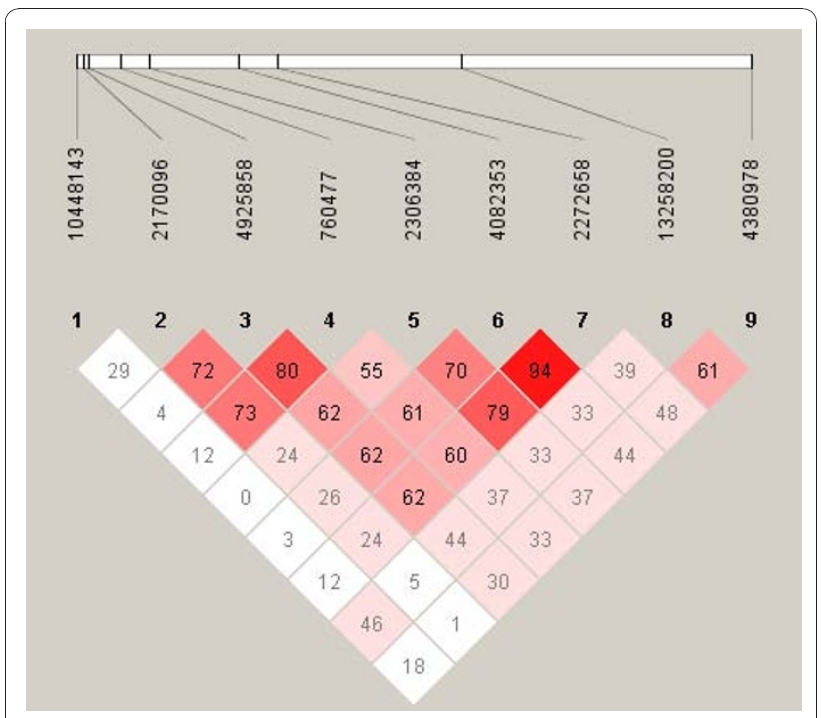

Figure 2 Relative position of SNPs and linkage disequilibrium map for NFKBIL2 in the Kenyan populations studied.

Polymorphisms are identified by their dbSNP rs numbers, and their relative positions are marked by vertical lines within the white horizontal bar. Numbers within squares indicate the $D^{\prime}$ value expressed as a percentile. Red squares indicate pairs in strong linkage disequilibrium (LD) with $L O D$ scores for $L D \geq 2$, pink squares $D^{\prime}<1$ with $L O D \geq 2$, and white squares $D^{\prime}<1.0$ and $L O D<2$.

protection against IPD [10,31]. Interestingly, studies in animal populations have found that increased levels of genome-wide heterozygosity correlate with overall fitness, and more specifically with resistance to infectious disease; for example, resistance to bovine tuberculosis in the Iberian wild boar [32]. These animal studies raise the possibility that heterozygote advantage against infectious disease may be a more widespread phenomenon in humans than previously considered. The biological mechanisms that underlie this remain unclear, although in the setting of inflammatory signalling pathways it has been speculated that homozygote states may lead to extremes of inflammatory response that, under certain circumstances, are detrimental to the host, whereas heterozygosity may result in intermediate signalling that leads to an optimal inflammatory response [31]. Such a model will be further modified by environmental exposures, and differing burdens of bacterial disease may in part account for the observed variation in NFKBIL2 allele frequencies between European and African populations.

Finally, it is interesting that four out of the five $\mathrm{I} \kappa \mathrm{B}$ genes studied to date show apparent associations with susceptibility to IPD $[9,10]$. This further highlights the importance of the control of NF- $\kappa \mathrm{B}$ in the host immune response, and suggests that the remaining members of the $\mathrm{I} \kappa \mathrm{B}$ family are likely to be promising candidates for a role in pneumococcal susceptibility. Study of the genetic basis of NF- $\kappa \mathrm{B}$ inhibition may be increasingly relevant given current interest in the regulation of NF- $\kappa \mathrm{B}$ activity as a therapeutic target for inflammatory disease [33]. Within the field of infectious disease, inhibition of NF- $\kappa$ B has been demonstrated to improve outcome in animal models of sepsis and pneumococcal meningitis $[34,35]$. The anti-inflammatory activity of glucocorticoids is mediated at least in part through physical interference of the glucocorticoid receptor complex with NF- $\kappa$ B DNA binding and increased synthesis of

Table 6 NFKBIL2 polymorphism genotype frequencies in Kenyan children with bacteraemia (overall, Gram-positive, and pneumococcal) and controls

\begin{tabular}{|c|c|c|c|c|c|c|c|c|}
\hline \multirow[t]{2}{*}{$\begin{array}{l}\text { Polymorphism/location (major/ } \\
\text { minor allele) }\end{array}$} & \multirow[t]{2}{*}{ Status } & \multicolumn{3}{|c|}{ Genotype distribution $^{a}$} & \multirow[t]{2}{*}{ Total } & \multirow[t]{2}{*}{$\begin{array}{l}\text { Genotypic } 3 \times 2 \text { chi-square } \\
(P \text { value })\end{array}$} & \multicolumn{2}{|c|}{$\begin{array}{l}\text { Heterozygote } \\
\text { protection model }^{\text {b }}\end{array}$} \\
\hline & & $A A$ & $\mathrm{Aa}$ & aa & & & OR $(95 \% \mathrm{Cl})$ & $P$ value \\
\hline \multirow[t]{4}{*}{$\begin{array}{l}\text { rs4925858, }-3,771,5^{\prime} \text { upstream } \\
\text { (G/A) }\end{array}$} & Control & $\begin{array}{l}255 \\
(46.4 \%)\end{array}$ & $\begin{array}{l}247 \\
(44.9 \%)\end{array}$ & $\begin{array}{l}48 \\
(8.7 \%)\end{array}$ & 550 & $4.104(0.128)$ & $\begin{array}{l}0.80(0.64 \text { to } \\
1.00)\end{array}$ & 0.053 \\
\hline & Bacteraemia & $\begin{array}{l}343 \\
(49.9 \%)\end{array}$ & $\begin{array}{l}271 \\
(39.4 \%)\end{array}$ & $\begin{array}{l}73 \\
(10.6 \%)\end{array}$ & 687 & & & \\
\hline & $\begin{array}{l}\text { Gram-positive } \\
\text { bacteraemia }\end{array}$ & $\begin{array}{l}167 \\
(49.9 \%)\end{array}$ & $\begin{array}{l}125 \\
(37.3 \%)\end{array}$ & $\begin{array}{l}43 \\
(12.8 \%)\end{array}$ & 335 & $6.806(\mathbf{0 . 0 3 4})$ & $\begin{array}{l}0.73(0.55 \text { to } \\
0.96)\end{array}$ & 0.026 \\
\hline & $\begin{array}{l}\text { Pneumococcal } \\
\text { bacteraemia }\end{array}$ & $\begin{array}{l}83 \\
(48.8 \%)\end{array}$ & $\begin{array}{l}62 \\
(36.5 \%)\end{array}$ & $\begin{array}{l}25 \\
(14.7 \%)\end{array}$ & 170 & $6.900(\mathbf{0 . 0 3 2})$ & $\begin{array}{l}0.70(0.49 \text { to } \\
1.00)\end{array}$ & 0.052 \\
\hline \multirow[t]{4}{*}{ rs760477, -263, intron $4(\mathrm{C} / \mathrm{T})$} & Control & $\begin{array}{l}262 \\
(53.0 \%)\end{array}$ & $\begin{array}{l}192 \\
(38.9 \%)\end{array}$ & $\begin{array}{l}40 \\
(8.1 \%)\end{array}$ & 494 & $9.445(\mathbf{0 . 0 0 9})$ & $\begin{array}{l}0.68(0.53 \text { to } \\
0.87)\end{array}$ & 0.002 \\
\hline & Bacteraemia & $\begin{array}{l}403 \\
(60.6 \%)\end{array}$ & $\begin{array}{l}201 \\
(30.2 \%)\end{array}$ & $\begin{array}{l}61 \\
(9.2 \%)\end{array}$ & 665 & & & \\
\hline & $\begin{array}{l}\text { Gram-positive } \\
\text { bacteraemia }\end{array}$ & $\begin{array}{l}197 \\
(60.4 \%)\end{array}$ & $\begin{array}{l}97 \\
(29.8 \%)\end{array}$ & $\begin{array}{l}32 \\
(9.8 \%)\end{array}$ & 326 & $7.205(\mathbf{0 . 0 2 7})$ & $\begin{array}{l}0.67(0.49 \text { to } \\
0.90)\end{array}$ & 0.007 \\
\hline & $\begin{array}{l}\text { Pneumococcal } \\
\text { bacteraemia }\end{array}$ & $\begin{array}{l}93 \\
(56.4 \%)\end{array}$ & $\begin{array}{l}52 \\
(31.5 \%)\end{array}$ & $\begin{array}{l}20 \\
(12.1 \%)\end{array}$ & 165 & $4.259(0.119)$ & $\begin{array}{l}0.72(0.50 \text { to } \\
1.05)\end{array}$ & 0.090 \\
\hline
\end{tabular}

OR, odds ratio; $\mathrm{Cl}$, confidence interval. ${ }^{\mathrm{a}}$ Number of individuals (\%). ${ }^{\mathrm{b}}$ Comparison of heterozygotes [Aa] with homozygotes [AA + aa]. ${ }^{\mathrm{c}} 2 \times 2 \mathrm{chi}-\mathrm{squared}$ comparison, one degree of freedom. $P$ values below 0.05 are highlighted in bold. 
$\mathrm{I} \kappa \mathrm{B}$ [36], and there is some evidence of benefit from corticosteroids in the treatment of pneumococcal meningitis and perhaps also severe community-acquired pneumonia [37,38]. Taken together, these findings raise the intriguing possibility that anti-inflammatory treatments such as glucocorticoids may be more effective if tailored on the basis of an individual's genetic profile of $\mathrm{NF}-\kappa \mathrm{B}$ activation.

\section{Conclusions}

Our study demonstrates associations between common NFKBIL2 polymorphisms and susceptibility to IPD in European and African populations. These findings further support a central role for regulation of NF- $\kappa \mathrm{B}$ in human host defence against pneumococcal disease.

\section{Key messages}

- Common polymorphisms in the gene NFKBIL2 associate with susceptibility to IPD in European and African populations.

- The parallel study of disease phenotypes in European and African populations (a trans-ethnic mapping approach) facilitates fine-mapping of genetic associations within regions of strong LD.

- Genetic variation in control of the proinflammatory transcription factor NF- $\kappa \mathrm{B}$ appears to play a key role in host defence against pneumococcal disease.

\section{Abbreviations}

CCL5: C-C motif ligand 5; IKB: inhibitor of NF-KB; IL: interleukin; IPD: invasive pneumococcal disease; LD: linkage disequilibrium; NF: nuclear factor; OR: odds ratio; PCR: polymerase chain reaction; RANTES: 'regulated upon activation normal T cell expressed and secreted'; SNP: single nucleotide polymorphism; TNF: tumour necrosis factor.

\section{Acknowledgements}

The present study was supported by the Wellcome Trust, UK. SJC is a Wellcome Trust Clinical Research Fellow and is supported by the NIHR Biomedical Research Centre, Oxford. CCK is a scholar of the Agency for Science, Technology and Research (A-STAR), Singapore and member of the MBBS-PhD programme, Faculty of Medicine, National University of Singapore. AR is supported by the EU FP6 GRACE grant and the Academy of Finland. DWC is supported by the NIHR Biomedical Research Centre, Oxford. JAS is funded by the Wellcome Trust. TNW is funded by the Wellcome Trust, European Network 6 BioMalpar consortium Project and the MalariaGen Network funded by Bill and Melinda Gates. AVSH is a Wellcome Trust Principal Fellow. The funders had no role in study design, data collection and analysis, decision to publish, or preparation of the manuscript. This paper is published with the permission of the director of the Kenya Medical Research Institute.

\section{Author details}

${ }^{1}$ The Wellcome Trust Centre for Human Genetics, University of Oxford, Roosevelt Drive, Oxford OX3 7BN, UK. ${ }^{2}$ Oxford Centre for Respiratory Medicine, Churchill Hospital Site, Oxford Radcliffe Hospitals, Roosevelt Drive, Oxford OX3 7LJ, UK. ${ }^{3} \mathrm{NIHR}$ Oxford Biomedical Research Centre, Respiratory Medicine, John Radcliffe Hospital, Headley Way, Oxford OX3 9DU, UK. ${ }^{4}$ Current address: Division for Infectious Diseases, Genome Institute of Singapore, 60 Biopolis Street, Singapore. ${ }^{5}$ Current address: Section of Genomic Medicine, Imperial College London, Hammersmith Hospital, Du Cane Road, London W12 ONN, UK. ${ }^{6}$ Department of Paediatrics, John Radcliffe
Hospital, Headley Way, Oxford OX3 9DU, UK. ${ }^{7}$ Centre for Clinical Vaccinology and Tropical Medicine, Churchill Hospital, Roosevelt Drive, Oxford OX3 7LJ, UK. ${ }^{8}$ Kenya Medical Research Institute/Wellcome Trust Programme, Centre for Geographic Medicine Research, Coast, Kilifi District Hospital, P.O. Box 23080108, Kilifi, Kenya. ${ }^{9}$ Department of Microbiology, John Radcliffe Hospital, Headley Way, Oxford OX3 9DU, UK. ${ }^{10}$ Nuffield Department of Clinical Medicine, John Radcliffe Hospital, Headley Way, Oxford OX3 9DU, UK. ${ }^{11}$ INDEPTH Network, 11 Mensah Wood Street, East Legon, P. O. Box KD 213, Kanda, Accra, Ghana.

\section{Authors' contributions}

SJC, CCK and FOV performed genotyping and statistical analysis. SJC drafted the manuscript. SS, CEM, RJOD, NPD, NP, DWC, JAB, TNW and JAS enrolled patients, collected samples and data, and defined phenotypes. DWC, JAS and AVSH coordinated the study. SJC, CCK, FOV, AR, AW, DWC, JAB, TNW, JAS and AVSH contributed to the conception and design of the project. All authors read and approved the final manuscript.

\section{Competing interests}

The authors declare that they have no competing interests.

Received: 2 August 2010 Revised: 12 November 2010

Accepted: 20 December 2010 Published: 20 December 2010

\section{References}

1. Mizgerd JP: Lung infection - a public health priority. PLoS Med 2006, 3 e76.

2. Wardlaw T, Salama P, Johansson EW, Mason E: Pneumonia: the leading killer of children. Lancet 2006, 368:1048-1050.

3. World Health Organisation: Pneumococcal vaccines. Wkly Epidemiol Record 2003, 78:110-118.

4. Bogaert D, de Groot R, Hermans PWM: Streptococcus pneumoniae colonisation: the key to pneumococcal disease. Lancet Infect Dis 2004, 4:144-154.

5. Brouwer MC, de Gans J, Heckenberg SG, Zwinderman AH, van der Poll T, van de Beek D: Host genetic susceptibility to pneumococcal and meningococcal disease: a systematic review and meta-analysis. Lancet Infect Dis 2009, 9:31-44.

6. Amory-Rivier CF, Mohler J, Bedos JP, Azoulay-Dupuis E, Henin D, MuffatJoly M, Carbon C, Moine P: Nuclear factor-KB activation in mouse lung lavage cells in response to Streptococcus pneumoniae pulmonary infection. Crit Care Med 2000, 28:3249-3256.

7. Jones MR, Simms BT, Lupa MM, Kogan MS, Mizgerd JP: Lung NF-kB activation and neutrophils recruitment require IL-1 and TNF receptor signaling during pneumococcal pneumonia. J Immunol 2005, 175:7530-7535.

8. Puel A, Picard C, Ku CL, Smahi A, Casanova JL: Inherited disorders of NFKB-mediated immunity in man. Curr Opin Immunol 2004, 16:34-41.

9. Chapman SJ, Khor CC, Vannberg FO, Frodsham A, Walley A, Maskell NA, Davies CWH, Segal S, Moore CE, Gillespie SH, Denny P, Day NP, Crook DW, Davies RJO, Hill AVS: IKB genetic polymorphisms and invasive pneumococcal disease. Am J Respir Crit Care Med 2007, 176:181-187.

10. Chapman SJ, Khor CC, Vannberg FO, Rautanen A, Segal S, Moore CE, Davies RJO, Day NP, Peshu N, Crook DW, Berkley JA, Williams TN, Scott JA, Hill AVS: NFKBIZ polymorphisms and susceptibility to pneumococcal disease in European and African populations. Genes Immunity 2009, 11:319-325.

11. Ghosh S, May MJ, Kopp EB: NF-kB and Rel proteins: evolutionary conserved mediators of immune responses. Annu Rev Immunol 1998, 16:225-260.

12. Baldwin AS: The NF- $\mathrm{KB}$ and IкB proteins: new discoveries and insights. Annu Rev Immunol 1996, 14:649-681.

13. Siebenlist U, Brown K, Claudio E: Control of lymphocyte development by nuclear factor-кB. Nat Rev Immunol 2005, 5:435-445.

14. Ray P, Zhang DH, Elias JA, Ray A: Cloning of a differentially expressed IKBrelated protein. J Biol Chem 1995, 270:10680-10685.

15. Norman DAM, Barton PJR: Isolation, sequence, and chromosomal localisation of the human IKBR gene (NFKBIL2). Ann Hum Genet 2000, 64:15-23. 
16. Ray P, Yang L, Zhang DH, Ghosh SK, Ray A: Selective up-regulation of cytokine-induced RANTES gene expression in lung epithelial cells by overexpression of IKBR. J Biol Chem 1997, 272:20191-20197.

17. Roy S, Knox K, Segal S, Griffiths D, Moore CE, Welsh Kl, Smarason A, Day NP, McPheat WL, Crook DW, Hill AV, Oxford Pneumococcal Surveillance Group: MBL genotype and risk of invasive pneumococcal disease: a casecontrol study. Lancet 2002, 359:1569-1573.

18. Wellcome Trust Case Control Consortium: Genome-wide association study of 14,000 cases of seven common diseases and 3,000 shared controls. Nature 2007, 447:661-678.

19. Berkley JA, Lowe BS, Mwangi I, Williams T, Bauni E, Mwarumba S, Ngetsa C, Slack MP, Njenga S, Hart CA, Maitland K, English M, Marsh K, Scott JA: Bacteremia among children admitted to a rural hospital in Kenya. N Engl J Med 2005, 352:39-47.

20. NCBI dbSNP. [http://www.ncbi.nlm.nih.gov]

21. Ensembl Genome Browser. [http://www.ensembl.org].

22. Jurinke C, van den Boom D, Cantor CR, Koster H: The use of MassARRAY technology for high throughput genotyping. Adv Biochem Eng Biotechnol 2002, 77:57-74.

23. Barrett JC, Fry B, Maller J, Daly MJ: Haploview: analysis and visualization of LD and haplotype maps. Bioinformatics 2005, 21:263-265.

24. Gabriel SB, Schaffner SF, Nguyen H, Moore JM, Roy J, Blumenstiel B, Higgins J, DeFelice M, Lochner A, Faggart M, Liu-Cordero SN, Rotimi C, Adeyemo A, Cooper R, Ward R, Lander ES, Daly MJ, Altshuler D: The structure of haplotype blocks in the human genome. Science 2002, 296:2225-2229.

25. NCI-NHGRI Working Group on Replication in Association Studies: Replicating genotype-phenotype associations. Nature 2007, 447:655-660.

26. Bernatoniene J, Zhang Q, Dogan S, Mitchell TJ, Paton JC, Finn A: Induction of CC and CXC chemokines in human antigen-presenting dendritic cells by the pneumococcal proteins pneumolysin and $\mathrm{CbpA}$, and the role played by toll-like receptor $4, \mathrm{NF}-\mathrm{KB}$, and mitogen-activated protein kinases. J Infect Dis 2008, 198:1823-1833.

27. Palaniappan $R$, Singh $S$, Singh UP, Singh $R$, Ades EW, Briles DE, Hollingshead SK, Royal W, Sampson JS, Stiles JK, Taub DD, Lillard JW Jr: CCL5 modulates pneumococcal immunity and carriage. J Immunol 2006, 176:2346-2356

28. Dean M, Carrington M, O'Brien SJ: Balanced polymorphism selected by genetic versus infectious human disease. Annu Rev Genomics Hum Genet 2002, 3:263-292

29. Mead S, Stumpf MP, Whitfield J, Beck JA, Poulter M, Campbell T, Uphill JB, Goldstein D, Alpers M, Fisher EM, Collinge J: Balancing selection at the prion protein gene consistent with prehistoric kurulike epidemics. Science 2003, 300:640-643.

30. Carrington M, Nelson GW, Martin MP, Kissner T, Vlahov D, Goedert JJ, Kaslow R, Buchbinder S, Hoots K, O'Brien SJ: HLA and HIV-1: heterozygote advantage and B*35-CW*04 disadvantage. Science 1999, 283:1748-1752.

31. Khor CC, Chapman SJ, Vannberg FO, Dunne A, Murphy C, Ling EY, Frodsham AJ, Walley AJ, Kyrieleis O, Khan A, Aucan C, Segal S, Moore CE, Knox K, Campbell SJ, Lienhardt C, Scott A, Aaby P, Sow OY, Grignani RT, Peshu N, Williams TN, Davies RJO, Kwiatkowski DP, Day NP, Crook DW Marsh K, Berkley JA, O'Neill LAJ, Hill AVS: A functional variant in MAL/ TIRAP and protection against invasive pneumococcal disease, bacteraemia, malaria and tuberculosis. Nat Genet 2007, 39:523-528.

32. Acevedo-Whitehouse K, Vicente J, Gortazar C, Hofle U, Fernandez-deMera IG, Amos W: Genetic resistance to bovine tuberculosis in the Iberian wild boar. Mol Ecol 2005, 14:3209-3217.

33. Karin M, Yamamoto $Y$, Wang QM: The IKK NF-KB system: a treasure trove for drug development. Nat Rev Drug Discov 2004, 3:17-26.

34. Abraham E: Alterations in cell signaling in sepsis. Clin Infect Dis 2005, 41: S459-S64.

35. Koedel U, Bayerlein I, Paul R, Sporer B, Pfister HW: Pharmacological interference with NF-kB activation attenuates central nervous system complications in experimental pneumococcal meningitis. J Infect Dis 2000, 182:1437-1445

36. Rhen T, Cidlowski JA: Antiinflammatory action of glucocorticoids - new mechanisms for old drugs. N Engl J Med 2005, 353:1711-1723.

37. van de Beek D, de Gans J, Tunkel AR, Wijdicks EF: Community-acquired bacterial meningitis in adults. N Engl J Med 2006, 354:44-53.
38. Salluh Jl, Póvoa P, Soares M, Castro-Faria-Neto HC, Bozza FA, Bozza PT: The role of corticosteroids in severe community-acquired pneumonia: a systematic review. Crit Care 2008, 12:R76.

doi:10.1186/cc9377

Cite this article as: Chapman et al:: Common NFKBIL2 polymorphisms and susceptibility to pneumococcal disease: a genetic association study. Critical Care 2010 14:R227.

\section{Submit your next manuscript to BioMed Central and take full advantage of:}

- Convenient online submission

- Thorough peer review

- No space constraints or color figure charges

- Immediate publication on acceptance

- Inclusion in PubMed, CAS, Scopus and Google Scholar

- Research which is freely available for redistribution

Submit your manuscript at www.biomedcentral.com/submit
C Biomed Central 